\title{
Azimuthally invariant Mueller-matrix mapping of biological optically anisotropic network
}

Yu. O. Ushenko, O. Vanchuliak, G. B. Bodnar, V. O. Ushenko, M. Grytsyuk, et al. 


\title{
Azimuthally invariant Mueller-matrix mapping of biological optically anisotropic network
}

\author{
Yu.O. Ushenko ${ }^{a}$, O. Vanchuliak ${ }^{b}$, G.B. Bodnar ${ }^{b}$, V.O. Ushenko ${ }^{a}$, M. Grytsyuk ${ }^{b}$, \\ N. Pavlyukovich ${ }^{\mathrm{b}}$, O.V. Pavlyukovich ${ }^{\mathrm{b}}$, O. Antonyuk ${ }^{\mathrm{b}}$ \\ ${ }^{a}$ Chernivtsi National University, 2 Kotsyubinsky Str., Chernivtsi, 58012, Ukraine \\ ${ }^{\mathrm{b}}$ Bukovinian State Medical University, Chernivtsi, 58000, Ukraine
}

\begin{abstract}
A new technique of Mueller-matrix mapping of polycrystalline structure of histological sections of biological tissues is suggested. The algorithms of reconstruction of distribution of parameters of linear and circular dichroism of histological sections liver tissue of mice with different degrees of severity of diabetes are found. The interconnections between such distributions and parameters of linear and circular dichroism of liver of mice tissue histological sections are defined. The comparative investigations of coordinate distributions of parameters of amplitude anisotropy formed by Liver tissue with varying severity of diabetes (10 days and 24 days) are performed. The values and ranges of change of the statistical (moments of the 1st -4 th order) parameters of coordinate distributions of the value of linear and circular dichroism are defined. The objective criteria of cause of the degree of severity of the diabetes differentiation are determined.
\end{abstract}

Keywords: polarization; Fourier optics and signal processing; imaging systems; medical and biological imaging.

\section{INTRODUCTION}

The foundations of the traditional Müller-matrix polarimetry are set forth in a series of publications ${ }^{1-13}$.

A new step was the basics of laser polarimetry of optically thin non-depolarizing layers creation ${ }^{14-31}$. ]. The question of studying the optical anisotropy of diffuse depolarizing layers remains open ${ }^{32}$. This work is aimed at the development and substantiation of the methods of Mueller-matrix mapping and 2D reconstruction of distribution of parameters of linear and circular dichroism of mice liver tissue with different degrees of severity of diabetes.

\section{THEORY}

The theoretical bases of Mueller matrix approach to describe the interaction of optical radiation with depolarizing layers are shown in a series of publications ${ }^{24-31}$. By averaging the generalization of this theory, we have found the relationships between the parameters of the amplitude anisotropy and the elements of the Muller matrix of the diffuse layer combinations

$$
\begin{aligned}
& L D=\ln \left(\frac{M_{14}}{M_{41}}\right) ; \\
& L D^{*}=\ln \left(\frac{M_{24}}{M_{42}}\right) ; \\
& C B=\ln \left(\frac{M_{13}}{M_{31}}\right) ;
\end{aligned}
$$

Here $L D$ - linear dichroism for $\gamma=0^{\circ} ; L D^{*}$ - linear dichroism for $\gamma=45^{\circ} ; C D$ circular dichroism determined by the following relations: 
Therefore using the ideologies of differential data analysis of Mueller-matrix mapping allowed us to obtain a set of algorithms (equations (1) - (3)) of polarization reproduction of mean values of the parameters of amplitude anisotropy of biological layer polycrystalline component.

\section{MATERIALS AND METHODS}

Experimental investigations of Mueller matrix elements coordinate distributions were performed in the classical setup of polarimeter ${ }^{14,15}$.

\section{RESULTS AND DISCUSSION}

As objects of investigation we chose the most frequently used histological sections (geometrical thickness $d=30 \mu \mathrm{m} \div 35 \mu \mathrm{m}$ ) of biopsy of liver tissue of mice with different degrees of diabetes severity (10 days and 24 days) in multiple scattering regime is realized. In other words, such standard samples are appeared to be partly depolarizing (attenuation coefficient $\tau>0.01 \approx 0.056 \div 0.078$ ) of laser radiation.

From the medical point of view two groups of мышей with the following diagnoses, prepared according to standard technique on the freezing microtome were formed:

- group 1 - diabetes duration 10 days;

- group 2 - diabetes duration 24 days.

The measured distributions $q \equiv\left\{M_{i k}\right\}$ were objectively analyzed within the statistical approach ${ }^{16}$ - the set of statistical moments of the 1 st- 4 th order was determined.

The data of Mueller-matrix dichroism tomography allowed us to estimate the polycrystalline structure of the myocardium samples in more detail (quantitatively) of Figs. 1-2 show the dichroism tomograms $\{\Delta \tau(m \times n) ; \Delta \chi(m \times m)\}$ and the histograms of the distribution of parameters of amplitude (relation (1), (3)) anisotropy of the mice liver histological sections obtained using this method.
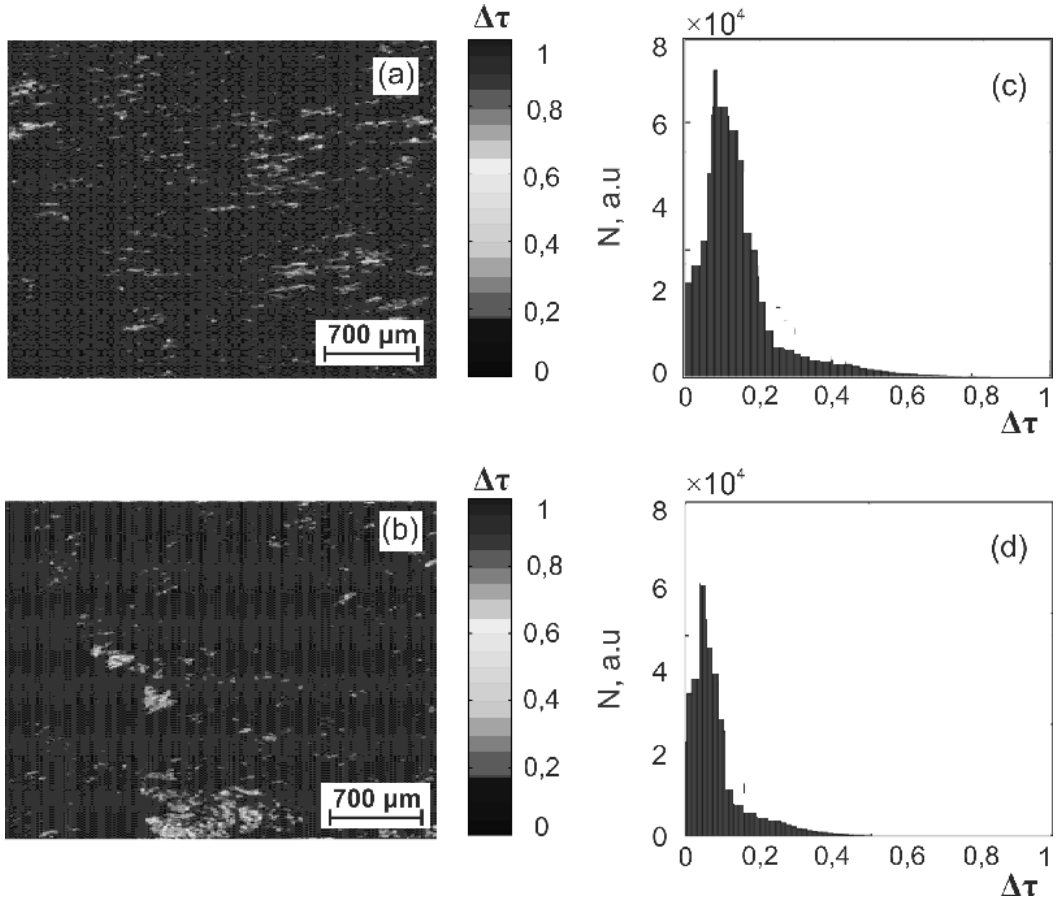

Fig. 1. Dichroism tomograms ((a),(b)) and histograms ((c),(d)) of the distributions $\Delta \tau(m \times n)$ of mice liver tissue histological sections from group $1((a),(c))$ and group 2 ((b),(d)). 

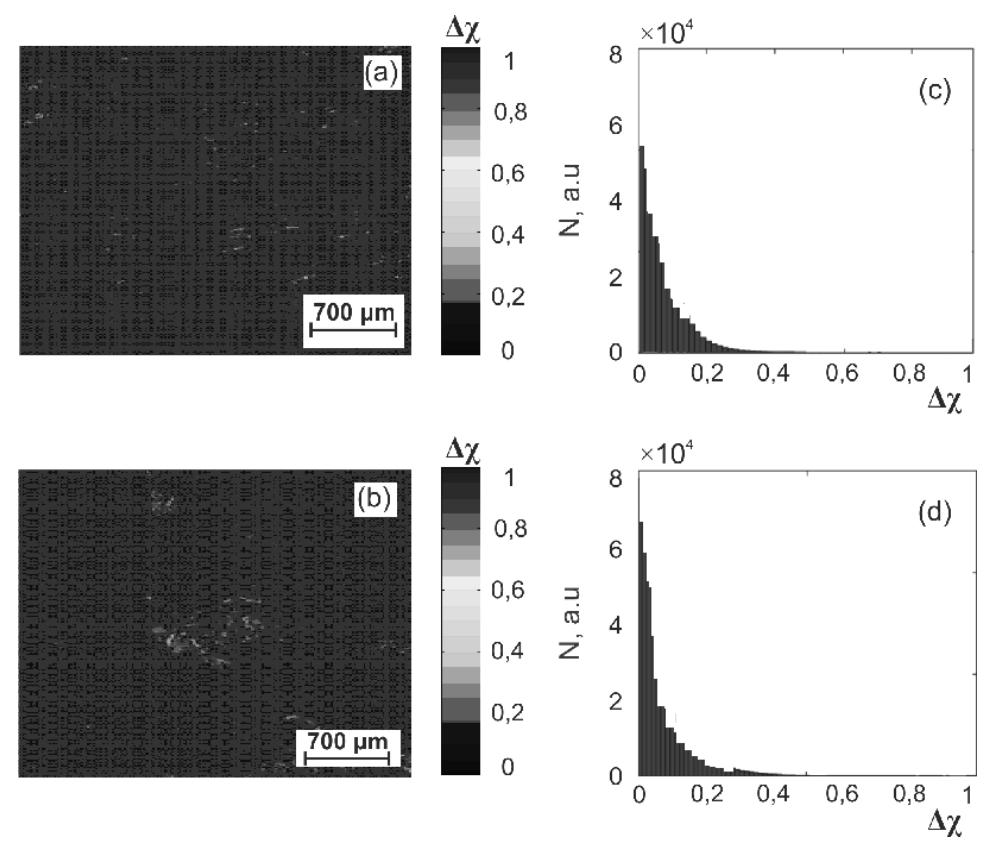

Fig. 2. Dichroism tomograms ((a),(b)) and histograms ((c),(d)) of the distributions $\Delta \chi(m \times n)$ of mice liver tissue histological sections from group $1((a),(c))$ and group $2((b),(d))$.

The differentiation between the group 1 and group 2 was determined by using of the following methodology ${ }^{35-37}$ :

- within each set of values of statistical moments $Z_{i=1 ; 2 ; 3 ; 4}$ we determined the average value $\widetilde{Z}_{i=1 ; 2 ; 3 ; 4}$ and standard deviation $\sigma_{i=1 ; 2 ; 3 ; 4}$;

- differences between the statistical sets $Z_{i=1 ; 2 ; 3 ; 4}$ were significant in the case when the average value $\widetilde{Z}_{i=1 ; 2 ; 3 ; 4}$ within the group 1 didn't "overlap" with the standard deviation $\sigma_{i=1: 2: 3 ; 4}$ within group 2 and vice versa.

- for every statistical moments traditional for probative medicine operational characteristics: sensitivity $\left(S e=\frac{a}{a+b} 100 \%\right)$, specificity $\left(S p=\frac{c}{c+d} 100 \%\right)$ and balanced accuracy $\left(A c=\frac{S e+S p}{2}\right)$, where $a$ and $b$ are the number of correct and wrong diagnoses within group 2;c and $d$ - the same within group 1 were determined.

The comparative analysis of the data obtained (Table 1) showed that the differences between the values of average $\widetilde{Z}_{i=1 ; 2 ; 3 ; 4}$ moments of all orders are statistically valid.

Table 1 Parameters of statistical structure of dichroism tomograms coordinate distributions.

\begin{tabular}{|c|c|c|c|c|}
\hline \multirow{2}{*}{ Parameters } & \multicolumn{2}{|c|}{$\Delta \tau(m \times n)$} & \multicolumn{2}{c|}{$\Delta \chi(m \times n)$} \\
\cline { 2 - 5 } & 10 days & 21 days & 10 days & 21 days \\
\hline$Z_{1}$ & $0.093 \pm$ & $0.052 \pm$ & $0.071 \pm$ & $0.069 \pm$ \\
& 0.0072 & 0.0043 & 0.0053 & 0.0044 \\
\hline$Z_{2}$ & $0.13 \pm$ & $0.089 \pm$ & $0.12 \pm$ & $0.094 \pm$ \\
& 0.0078 & 0.0054 & 0.0093 & 0.0071 \\
\hline$Z_{3}$ & $1.12 \pm$ & $0.78 \pm$ & $1.39 \pm$ & $1.08 \pm$ \\
& 0.072 & 0.0 .56 & 0.11 & 0.091 \\
\hline$Z_{4}$ & $1.79 \pm$ & $1.02 \pm$ & $1.45 \pm$ & $1.23 \pm$ \\
& 0.14 & 0.069 & 0.11 & 0.104 \\
\hline
\end{tabular}


Table 2 presents the parameters of information value of method of dichroism tomography of optical anisotropy of histological sections of biopsy of mice liver tissue with different degrees of severity of diabetes.

Table 2 Operational characteristics of the method of Mueller-matrix tomography of optical anisotropy of histological sections of mice liver tissue with different degrees of severity of diabetes

\begin{tabular}{|c|c|c|c|}
\hline Parameters & $Z_{i}$ & $\Delta \tau(m \times n)$ & $\Delta \chi(m \times n)$ \\
\hline \multirow{4}{*}{$A c\left(Z_{i}\right)$} & $Z_{1}$ & $81 \%$ & $64 \%$ \\
\cline { 2 - 4 } & $Z_{2}$ & $69 \%$ & $67 \%$ \\
\cline { 2 - 4 } & $Z_{3}$ & $86 \%$ & $74 \%$ \\
\cline { 2 - 4 } & $Z_{4}$ & $92 \%$ & $71 \%$ \\
\hline
\end{tabular}

The obtained results enable to state a rather high level of accuracy of dichroism tomography. According to the criteria of probative medicine ${ }^{31}$ the parameters $A c(\Delta \tau) \sim 85 \%$ correspond to good quality, while $A c(\Delta \tau)>90 \%$ - to high quality.

\section{CONCLUSION}

The efficiency of the developed technique of Mueller-matrix tomography in the diagnostics of the mice liver tissue degree of diabetes severity was demonstrated.

The differentiation criteria between diabetic changes in mice liver tissue on the basis of the statistical (statistical moments of the 1st -4 th order) analysis of dichroism tomograms are defined.

\section{REFERENCES}

[1] Tuchin V.V., [Tissue Optics: Light Scattering Methods and Instruments for Medical Diagnosis] second edition, SPIE Press, Bellingham, WA, PM 166, (2007).

[2] Bickel S., Bailey W. M., "Stokes vectors, Mueller matrices, and polarization of scattered light", Am. J. Phys. 53 468-478 (1985).

[3] Wang X., Yao G., Wang L. - H., "Monte Carlo model and single-scattering approximation of polarized light propagation in turbid media containing glucose" Appl. Opt. 41, 792-801 (2002).

[4] Wang X., Wang L. - H., "Propagation of polarized light in birefringent turbid media: a Monte Carlo study", J. Biomed. Opt. 7, 279-290 (2002).

[5] Tuchin V. V., Wang L. and Zimnyakov D. À., [Optical Polarization in Biomedical Applications], New York, USA, (2006).

[6] Chipman R. A., [Polarimetry in Handbook of Optics: Vol. I- Geometrical and Physical Optics, Polarized Light, Components and Instruments], M. Bass, Ed., McGraw-Hill Professional, New York, 22.1-22.37 (2010).

[7] Ghosh N., Wood M. F. G. and Vitkin I. A., [Polarized light assessment of complex turbid media such as biological tissues via Mueller matrix decomposition in Handbook of Photonics for Biomedical Science], V.V. Tuchin, Ed., CRC Press, Taylor \& Francis Group, London, 253-282 (2010).

[8] Jacques S. L., [Polarized light imaging of biological tissues in Handbook of Biomedical Optics], D. Boas, C. Pitris, and N. Ramanujam, Eds., CRC Press, Boca Raton, London, New York, 649-669 (2011).

[9] Ghosh N., Vitkin I. A., "Tissue polarimetry: concepts, challenges, applications and outlook", J. Biomed. Opt. 16, 110801 (2011).

[10] Angelsky, O. V., Bekshaev, A. Ya., Maksimyak, P. P., Maksimyak, A. P., Hanson, S. G., "Measurement of small light absorption in microparticles by means of optically induced rotation," Optics Express 23(6), 7152-7163 (2015).

[11] Angelsky, O.V., Tomka, Y.Y., Ushenko, A.G., Ushenko, Y.G., Yermolenko, S.B., "2-D tomography of biotissue images in pre-clinic diagnostics of their pre-cancer states," Proc. SPIE., 5972, 158-162, (2005). 
[12] Angelsky, O.V., Besaha, R.N., Mokhun, A.I., Mokhun, I.I., Sopin, M.O., Soskin, M.S., "Singularities in vectoral fields," Proc. SPIE, 40-54, (1999).

[13] Polyanskii, V.K., Angelsky, O.V., Polyanskii, P.V., "Scattering-induced spectral changes as a singular optical effect," Optica Applicata 32 (4), 843-848, (2002).

[14] Ushenko A.G., Pishak V.P., [Laser Polarimetry of Biological Tissue: Principles and Applications, Handbook of Coherent-Domain Optical Methods: Biomedical Diagnostics, Environmental and Material Science], 239-321 (2004).

[15] Ushenko Yu.A., Boychuk T.M., Bachynsky V.T., Mincer O.P., [Diagnostics of Structure and Physiological State of Birefringent Biological Tissues: Statistical, Correlation and Topological Approaches, Handbook of CoherentDomain Optical Methods], Springer Science+Business Media, p. 107 (2013).

[16] Ushenko Yu.A., Ushenko V.A., Dubolazov A.V., Balanetskaya V.O., Zabolotna N.I., "Mueller-matrix diagnostics of optical properties of polycrystalline networks of human blood plasma", Optics and Spectroscopy 112, 884-892 (2012).

[17] Ushenko V.A., Dubolazov O.V., Karachevtsev A.O., "Two wavelength Mueller matrix reconstruction of blood plasma films polycrystalline structure in diagnostics of breast cancer", Appl. Opt. 53 B128-B139 (2014).

[18] Ushenko Y.A., Koval G.D., Ushenko A.G., Dubolazov O.V., Ushenko V.A., Novakovskaia O.Yu., "Muellermatrix of laser-induced autofluorescence of polycrystalline films of dried peritoneal fluid in diagnostics of endometriosis", J. Biomed. Opt. 21(7) 071116 (2016).

[19] Ushenko A.G., Dubolazov A.V., Ushenko V.A., Novakovskaya O.Y., "Statistical analysis of polarizationinhomogeneous fourier spectra of laser radiation scattered by human skin in the tasks of differentiation of benign and malignant formations", J. Biomed. Opt. 0001, 21(7), 071110 (2016).

[20] Prysyazhnyuk V.P., Ushenko Yu.A., Dubolazov A.V., Ushenko A.G., Ushenko V.A., "Polarization-dependent laser autofluorescence of the polycrystalline networks of blood plasma films in the task of liver pathology differentiation", Appl. Opt. 55, B126-B132 (2016).

[21] Azzam R. M. A., "Propagation of partially polarized light through anisotropic media with or without depolarization", J. Opt. Soc. Am. 68, 1756-1767 (1978).

[22] Jones R.C., "A new calculus for the treatment of optical systems. VII properties of the N-matrices", J. Opt. Soc. Am. 38, 671-685 (1948).

[23] Ortega-Quijano N., Arce-Diego J.L., "Mueller matrix differential decomposition", Opt. Letters 36, 1942-1944 (2011).

[24] Ortega-Quijano N., Arce-Diego J.L., "Depolarizing differential Mueller matrices", Opt. Letters 36, 2429-2431 (2011).

[25] Angelsky, O. V., Gorsky, M. P., Hanson, S. G., Lukin, V. P., Mokhun, I. I., Polyanskii, P. V., Ryabiy, P. A., "Optical correlation algorithm for reconstructing phase skeleton of complex optical fields for solving the phase problem," Opt. Exp. 22(5), 6186-6193 (2014).

[26] Ossikovski R., Devlaminck V., "General criterion for the physical reliability of the differential Mueller matrix", Opt. Lett. 39, 1216-1219 (2014).

[27] Angelsky, P. O., Ushenko, A. G., Dubolazov, A. V., Sidor, M. I., Bodnar, G. B., Koval, G., Trifonyuk, L., “The singular approach for processing polarization-inhomogeneous laser images of blood plasma layers," Journal of Optics, 15(4), 044030 (2013).

[28] Dubolazov, A. V., Marchuk, V., Olar, O. I., Bachinskiy, V. T., Vanchuliak, O. Y., Pashkovska, N. V., Kostiuk, S. V., "Multiparameter correlation microscopy of biological fluids polycrystalline networks," In Eleventh International Conference on Correlation Optics, International Society for Optics and Photonics, pp. 90661Y90661Y (2013).

[29] Ushenko, O., Dubolazov, A., Balanets' ka, V., Karachevtsev, A., Sydor, M., "Wavelet analysis for polarization inhomogeneous laser images of blood plasma," Proc. SPIE. Vol. 8338 (2011).

[30] Ushenko, V. A., O. V. Dubolazov, A. O. Karachevtsev, "Two wavelength Mueller matrix reconstruction of blood plasma films polycrystalline structure in diagnostics of breast cancer," Applied optics 53(10), B128-B139 (2014).

[31] Pérez-Cárceles M.D., Noguera J., Jiménez J.L., Martínez P., Luna A., Osuna E., "Diagnostic efficacy of biochemical markers in diagnosis post-mortem of ischaemic heart disease", Forensic Science International 142, 17 (2004).

[32] Martínez Díaz F., Rodríguez-Morlensín M., Pérez-Cárceles M.D., Noguera J., Luna A. and Osuna E., "Biochemical analysis and immunohistochemical determination of cardiac troponin for the postmortem diagnosis of myocardial damage", Histol. Histopathol. 20, 475-481 (2005). 
[33] Cassidy L.D., "Basic concepts of statistical analysis for surgical research", Journal of Surgical Research 128, 199206 (2005).

[34] O.V. Angelsky, S.G. Hanson, P.P. Maksimyak, A.P. Maksimyak, C.Yu. Zenkova, P.V. Polyanskii, and D.I. Ivanskyi, "Influence of evanescent wave on birefringent microplates," Opt. Express 25, 2299-2311 (2017).

[35] Angelsky, O. V., Bekshaev, A. Ya., Maksimyak, P. P., Maksimyak, A. P., Hanson, S. G., Kontush, S. M., "Controllable generation and manipulation of micro-bubbles in water with absorptive colloid particles by $\mathrm{CW}$ laser radiation," Opt. Express 25, 5232-5243 (2017).

[36] Angelsky, O. V., Bekshaev, A. Ya., Maksimyak, P. P., Maksimyak, A. P., Hanson, S. G., Zenkova, C. Yu., "Selfdiffraction of continuous laser radiation in a disperse medium with absorbing particles," Optics Express 21(7), 8922-8938, (2013).

[37] Angelsky, O. V., Bekshaev, A. Ya., Maksimyak, P. P., Maksimyak, A. P., Hanson, S. G., Zenkova, C. Yu., "Selfaction of continuous laser radiation and Pearcey diffraction in a water suspension with light-absorbing particles," Optics Express 22(3), 2267-2277, (2014). 